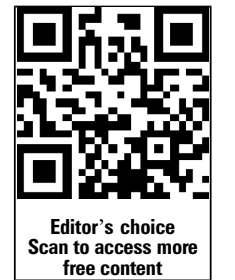

- Additional material is published online only. To view please visit the journal online (http://dx.doi.org/10.1136/jech2014-204182).

${ }^{1}$ Pacific Institute for Research and Evaluation, Calverton, Maryland, USA

${ }^{2}$ Faculty of Health Sciences, Centre for Population Health Research, Curtin University, Perth, Australia

${ }^{3}$ Centers for Disease Control and Prevention, National Center for Injury Prevention and Control, Atlanta, Georgia, USA

${ }^{4}$ Johns Hopkins Center for Injury Research and Policy, Johns Hopkins Bloomberg School of Public Health, Baltimore, Maryland, USA ${ }^{5}$ Econometrica, Inc., Bethesda, Maryland, USA

\section{Correspondence to} Dr Ted R Miller, Pacific Institute for Research and Evaluation, 814 Bromley St, Silver Spring, MD 20902, USA; miller@pire.org

Received 20 March 2014 Revised 16 June 2014 Accepted 6 August 2014 Published Online First 27 August 2014

\title{
Increasing smoke alarm operability through theory-based health education: a randomised trial
}

\author{
Ted R Miller, ${ }^{1,2}$ Gwen Bergen, ${ }^{3}$ Michael F Ballesteros, ${ }^{3}$ Soma Bhattacharya, ${ }^{1}$ \\ Andrea Carlson Gielen, ${ }^{4}$ Monique S Sheppard ${ }^{5}$
}

\section{ABSTRACT}

Background Although working smoke alarms halve deaths in residential fires, many households do not keep alarms operational. We tested whether theory-based education increases alarm operability.

Methods Randomised multiarm trial, with a single arm randomly selected for use each day, in low-income neighbourhoods in Maryland, USA. Intervention arms: (1) Full Education combining a health belief module with a social-cognitive theory module that provided hands-on practice installing alarm batteries and using the alarm's hush button; (2) Hands-on Practice social-cognitive module supplemented by typical fire department education; (3) Current Norm receiving typical fire department education only. Four hundred and thirty-six homes recruited through churches or by knocking on doors in 2005-2008. Followup visits checked alarm operability in 370 homes (85\%) 1-3.5 years after installation. Main outcome measures: number of homes with working alarms defined as alarms with working batteries or hard-wired and number of working alarms per home. Regressions controlled for alarm status preintervention; demographics and beliefs about fire risks and alarm effectiveness.

Results Homes in the Full Education and Practice arms were more likely to have a functioning smoke alarm at follow-up (OR=2.77, 95\% Cl 1.09 to 7.03 ) and had an average of 0.32 more working alarms per home $(95 \% \mathrm{Cl}$ 0.09 to 0.56$)$. Working alarms per home rose $16 \%$. Full Education and Practice had similar effectiveness ( $p=0.97$ on both outcome measures).

Conclusions Without exceeding typical fire department installation time, installers can achieve greater smoke alarm operability. Hands-on practice is key. Two years after installation, for every three homes that received hands-on practice, one had an additional working alarm.

Trial registration number http://www.clinicaltrials.gov number NCT00139126.

\section{INTRODUCTION}

Working smoke alarms reduce deaths in residential fires by at least $48 \%{ }^{1-3}$ Getting homes to check and change batteries to keep alarms operational, however, has proven difficult. ${ }^{4}$ Nationally, $96 \%$ of American homes report having smoke alarms, but only $80 \%$ report having working or operable alarms-alarms that are hard-wired or have working batteries. ${ }^{5}$ This percentage is much lower in low-income areas where typically $15-50 \%$ of smoke alarms do not work properly. ${ }^{3}{ }^{6-12}$ A King County, Washington programme that installed smoke alarms in owner-occupied lower income homes found $20 \%$ were not working-almost always deliberately-at 6 months and 23\% at
15 months postinstallation. ${ }^{13}$ In rural Iowa, $27 \%$ of alarms were not working at 42 months postinstallation. ${ }^{14}$ Nationally, in homes with fires attended by fire departments during 2003-2006, 31\% lacked alarms and $21 \%$ ( $30 \%$ of those with alarms) had only non-working alarms. ${ }^{1}$ Using a fire investigation database, we reviewed all 402 home structural fires investigated in Prince Georges' County, Maryland in 2001; 25\% of homes had working smoke alarms; $50 \%$ had non-working alarms and $25 \%$ lacked alarms.

A theory-based education programme with demonstrated effectiveness increasing long-term operability of smoke alarms seems a logical component for alarm installation programmes, yet none exists. Fire departments and community groups that install alarms almost always educate recipients about fire safety and alarm battery maintenance. When we reviewed a sample of these education programmes, almost none were theory-based. Their effectiveness also was largely unevaluated. Indeed, reviews of more than 55 home fire injury prevention interventions conclude that none are theory based. ${ }^{15}$ Although door-to-door canvassing and installation programmes have demonstrated effectiveness at increasing homes with alarms installed, ${ }^{4}{ }^{16}$ no education programme has the proven ability to assure smoke alarms continue to have working batteries. ${ }^{12} 17$

Our research objectives were to develop and evaluate the outcomes of theory-based education designed to increase the number of smoke alarms kept operational.

\section{METHODS}

\section{Design and intervention}

This study was a multiarm parallel trial with random assignment of homes with equal probability into two treatment arms and a comparison arm (1:1:1 allocation). The arms were:

1. Full Theory-Driven Education (Full Education) - an educational programme based on the health belief model integrated with hands-on practice based on the observational learning, reinforcement and modelling precepts of socialcognitive theory ${ }^{18}$ The educational programme primarily addressed the individual-level factors that influence use of smoke alarms. These are beliefs that smoke alarms are effective in preventing fire injuries, that a fire at home is likely, that a fire in the home can result in injury and that one is capable of maintaining a smoke alarm in the home. ${ }^{15}$ These factors correspond to the health belief model constructs of perceived benefits, perceived susceptibility, perceived severity and self-efficacy. ${ }^{18}$ Observational 
learning based on social-cognitive theory reinforced the critically important self-efficacy construct in the health belief model. The social-cognitive module consisted exclusively of hands-on practice testing the battery, installing a replacement battery and using the hush button. As part of the practice effort, the resident installed batteries in the alarms we installed. We also completed the fire safety checklist that is standard in fire department installations. It requires a home tour and guides identification of home fire hazards, testing if existing alarms are working and decisions about how many alarms to install or replace and where to hang them. We chose the health belief model because it is an individual-level behaviour change theory developed to explain what factors are important in encouraging preventive health actions that many people are not adopting even though these actions have proven effectiveness. ${ }^{18}$ Observational learning, reinforcement and modelling precepts of social-cognitive theory were included as they explain how a person learns the behaviour and these factors reinforce self-efficacy. ${ }^{18}$ Online supplementary appendix A provides the practice module's script. The accompanying brochure and all other materials are available from the lead author without charge.

2. Focused Hands-on Practice (Practice) - a compressed model restricted to the hands-on practice module, typical fire department education (described below) and leaving a brochure describing alarm use and explaining the importance of changing batteries.

3. Comparison arm: Typical Fire Department Education (Current Norm)—generic fire department education including completion of a fire safety checklist and leaving a 'baseball card' with fire safety educational messages on the back. The messages cover fire escape planning and encourage smoke alarm testing and semiannual battery changes.

\section{Procedures}

We advertised ourselves as a home safety project. A health educator and an alarm installer comprised a visit team. Safety protocols dictated that the educator remain in the home while the installer worked.

Two master-level health educators trained on and delivered scripted education. Including research data collection, home visits averaged $45 \mathrm{~min}$ for all arms with wide variance.
Education took less time than installation if the resident stayed on topic. Visit duration, therefore, was sensitive to resident characteristics, not the education programme.

Table 1 summarises data collection forms and other activities associated with the visit. The knowledge, attitudes and behaviour (KAB) survey (see online supplementary appendix B) included four general questions about fire risks, 10 about smoke alarms, and 7 (which were not analysed) about fall risks. We designed KAB questions keyed to the stages in the health belief model, with emphasis on the barriers and facilitators, but did not validate them. The intake form had six questions about fire experience and eight about fall experience. We included questions about falls and installed touchlights in dark stairwells because we described the project as a home safety check. Participant behaviour might have changed if they knew our research focus was strictly on smoke alarm functionality. Of importance, this approach presented the comparison arm with more balanced safety messaging. The protocol was to leave existing alarms in place only if they had a hush button and 10-year batteries (zero homes qualified) or were hard-wired (two homes qualified). We created English and Spanish versions of all materials. All forms, procedures and modifications were approved by Pacific Institute for Research and Evaluation's (PIRE's) IRB. No harm resulted from this trial.

Installers used Kidde model 0916 ionisation smoke alarms with hush button. Manufacturer's specifications state that the alarms start chirping when $6 \%$ of battery charge remains. The alarms include test buttons that provide a second mode of testing operability. Installing batteries marked with nail polish allowed follow-up to differentiate resident-supplied batteries from our batteries that were still working. We bulk purchased and used Rayovac D1604 heavy duty 9-volt carbon-zinc batteries with an expiration date of April 2010, but installed longer lasting alkaline batteries in all alarms at follow-up.

Primary outcome measures were an increase in (1) number of homes with at least one working smoke alarm and (2) average number of smoke alarms working in each home.

\section{Recruitment, randomisation, and time schedule}

The trials were conducted in Maryland, USA. Installation began in September 2005 and ended in May 2008. Our initial power calculation targeted 1000 installation homes with follow-up per

Table 1 Content and ordering of the smoke alarm home visit and differences between arms

\begin{tabular}{|c|c|c|c|}
\hline Activity & $\begin{array}{l}\text { Full } \\
\text { Education }\end{array}$ & Practice & $\begin{array}{l}\text { Current } \\
\text { Norm }\end{array}$ \\
\hline 1. Consent form (in-home or at a church where the person made an installation appointment) & $X$ & $X$ & $\mathrm{X}$ \\
\hline 2. Knowledge, attitudes, behaviour (KAB) survey (see online supplementary appendix B) & $X$ & $\mathrm{X}$ & $\mathrm{X}$ \\
\hline 3. Intake form: address, date, arm number, educator, if consented & $\mathrm{X}$ & $\mathrm{X}$ & $\mathrm{X}$ \\
\hline 4. Household demographic form & $X$ & $\mathrm{X}$ & $\mathrm{X}$ \\
\hline $\begin{array}{l}\text { 5. Fire safety checklist (educator follows the script as the installer tests existing alarms and identifies where alarms } \\
\text { should be added or replaced) }\end{array}$ & $\mathrm{X}$ & $\mathrm{X}$ & $\mathrm{X}$ \\
\hline 6. Hands-on practice testing and changing the alarm battery and hushing the alarm; based on social-cognitive theory & $X$ & $\mathrm{X}$ & \\
\hline 7. Education based on the health belief model & $\mathrm{X}$ & & \\
\hline 8. Hand comprehensive fire education brochure & $X$ & & \\
\hline 9. Hand smoke alarm brochure & & $\mathrm{X}$ & \\
\hline 10. Hand fire department 'baseball card' & & $\mathrm{X}$ & $\mathrm{X}$ \\
\hline \multicolumn{4}{|l|}{ Simultaneously with $6 / 7$, a second staff member } \\
\hline a. Installed or put new batteries in smoke alarms & $\mathrm{X}$ & $\mathrm{X}$ & $x$ \\
\hline b. Installed battery-operated touch lights in stairwells if needed & $\mathrm{X}$ & $X$ & $x$ \\
\hline
\end{tabular}

\#, Number; KAB; knowledge, attitudes and behaviour. 
arm, which would support detection at the 95\% confidence level of a 4-6\% change in operability at follow-up assuming half of the comparison arm had an operable alarm.

Typically most residents canvassed by smoke alarm installers do not open the door. ${ }^{13}$ The objective was to learn how to increase alarm maintenance by those who accept an installation, not how to increase access to homes. Therefore, entry into our sample began when a resident age 18 or over consented to alarm installation, even if education was refused (three homes).

Initially recruitment used door-to-door weekday and weekend daylight canvassing in four low income neighbourhoods of suburban Prince Georges' County. Using census data, we grouped the neighbourhoods into contiguous target areas of roughly $60 \mathrm{occu}-$ pied dwelling units, then used computer-generated random numbers to select a simple random sample of target areas to canvas.

A change in county fire chief prior to the start of canvassing forced us to install without fire engine assistance, greatly reducing our ability to get doors answered. Randomising to practice (arm 2) stopped in February 2007 to increase the likelihood that the other two arms would achieve an adequate sample size. To inform that decision, without examining arm assignment, we conducted an interim analysis of the mean and variance of number of alarms functioning at enrolment, finding that two-thirds of the comparison arm had working alarms preintervention with an SD of 0.4 so adequate power to detect a $10 \%$ differential postintervention required only 100-200 installations in each arm. Because of a continuing sample shortfall, in January 2008, we added two Baltimore city recruitment streams: marketing at church services and canvassing in neighbourhoods where presence of a fire truck with flashing lights facilitated access to low -income homes in blocks the fire department targeted.

To simplify the health educators' task, we assigned all of a day's participants to one arm that was randomly selected by rolling a die each day when the team assembled.

Using pilot-tested procedures and materials, staff knocked on doors and sent letters to schedule follow-up visits to check alarm operability and to ask questions about alarm testing, fire experience, and fall experience. Although follow-up was not formally blinded, it generally was performed by the installers; they were unaware of arm assignment.

Ideally follow-up would not occur until all batteries we initially installed had died. Otherwise we could not distinguish cases where residents were maintaining alarms that did not yet need new batteries from cases where the alarms would have become inoperable when initial batteries died. Since no data existed on carbon-zinc battery life in smoke alarms, we hung 100 alarms at PIRE's offices. Their battery failure rate led us to wait at least 500 days before attempting to return to a home to check operability. However, we returned up to 4 months early to the last 40 homes with installed alarms because follow-up (and the grant) ended in September 2009.

\section{Statistical analysis}

Analytically, we compared outcomes in treatment versus Current Norm homes using ordinary least squares linear regression to analyse whether the number of working alarms grew significantly from baseline to follow-up and logistic regression to analyse whether presence of at least one working alarm at follow-up increased significantly. All analyses were conducted in STATA V.11 from Statacorp, College Station, Texas, USA during 2009-2011.

Before starting data analysis, we decided to include data from pilot test homes because neither methods nor materials changed after pilot-testing. A dummy variable in the regressions tested whether including pilot test data affected outcomes (which it did not).

Because outcomes for the two theory-based health education arms proved extremely similar and sample size was modest, most analyses combined the two arms. To handle missing income data, we coded missing income as 0 and added a 0-1 variable valued at 1 for those who refused the income question. Online supplementary appendix C describes all other model covariates and shows the covariate-adjusted regressions with each arm separate. Regression analyses included preintervention alarm status (whether any alarms were operable or number of operable alarms) as a predictor to adjust for any bias associated with differences in functioning between arms at enrolment. The analysis tested whether time to follow-up affected outcomes in homes where batteries we initially installed were not still working. We initially tested models with all demographic variables and all KAB fire and smoke alarm item variables. We excluded most variables lacking statistical significance from final models to minimise cases excluded due to missing data and avoid multicollinearity.

\section{RESULTS}

We installed smoke alarms in 436 homes. We completed follow-up visits to 370 homes (85\% of installations).

\section{Loss to follow-up}

The flow diagram (figure 1) summarises homes where we installed alarms and the reasons for loss to follow-up. Loss to follow-up by arm ranged from $12.8 \%$ to $17.6 \%$. The most frequent reasons for loss to follow-up included: (1) the home was vacant on follow-up or (2) no one answered the door during five weekday and/or weekend follow-up attempts and the resident did not respond to a follow-up letter. Time to follow-up averaged 24 months (table 2).

Of 370 homes with follow-up data, 46 were dropped from the outcome analysis for the reasons described in figure 1. Roughly $75 \%$ of installations entered the analysis, with minimal variation between arms. The most frequent reasons for dropping cases were that all original batteries were still working (meaning we followed up too soon to be able to tell if residents would have changed the batteries and maintained operability), all working alarms were replaced with hard-wired alarms (typically in gentrified homes), or the structure had converted to nonresidential use. Virtually all non-working alarms had dead batteries. No one used their alarm batteries for other uses. Residents readily admitted removing batteries that were missing; they blamed nuisance alarms.

When we returned to homes, turnover to new occupants was low in our sample, only $16 \%$ among the 184 homes (57\%) where we recorded this information.

\section{Demographics and alarm status at enrolment}

Among participating households, 70\% were headed by women. Among respondents, 85\% were black, 52\% were over age 60 and $68 \%$ had no children living with them (see online supplementary table C1). The sample was well-educated, with 39\% having taken some college courses, another $26 \%$ having completed college, and $18 \%$ with some graduate school. Just over $20 \%$ lived in Baltimore and $8 \%$ participated in the pilot test (computed from counts in figure 1). Thirteen educational sessions used Spanish materials.

At enrolment, $27 \%$ of homes had no working alarms; the average home had 1.3 working smoke alarms (table 2). Practice and Full Education homes had fewer working alarms than 


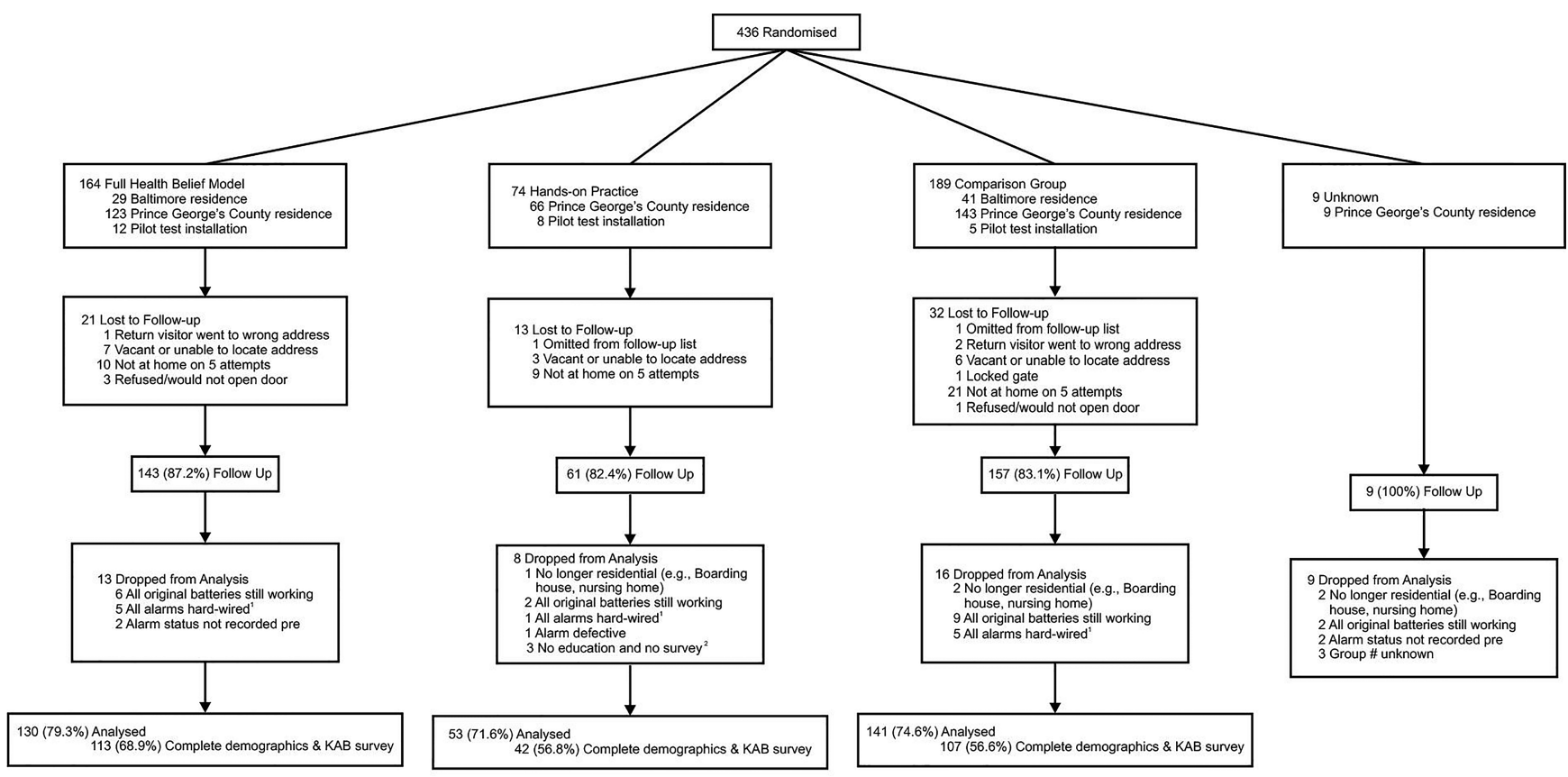

$\mathrm{KAB}=$ Knowledge, Attitude, and Behavior.

at both initial visit and follow-up. Follow-up visit staff failed to count the number of hard-wired alarms at five other homes.

follection or only spoke a language the attending education team could not speak. These homes were included in sensitivity analysis.

Figure 1 Flow diagram showing homes randomised and loss to follow-up and to analysis by reason and arm.

comparison arm homes at enrolment, but the difference was not statistically significant.

\section{Alarm status at follow-up and effects of intervention}

At follow-up and before adjustment for covariates, the percentage of homes without working alarms was smaller and the increase in working alarms per home was larger in homes that received Full Education, intermediate in Practice homes and lowest in Current Norm homes.
The analysis included 10\% of follow-ups where residents reported their alarm operability but did not allow re-entry to their homes (table 2). These cases were equally common among arms. In sensitivity analysis, excluding cases with self-reported operability minimally affected results.

Linear regression controlling for alarm status preinstallation showed that Practice or Full Education homes had significantly more alarms with operating batteries than Current Norm homes at follow-up (table 3). Income group and $\mathrm{KAB}$ prior to

Table 2 Alarm status by arm and time period

\begin{tabular}{|c|c|c|c|c|}
\hline Arm & Full Education & Practice & Current Norm & Total \\
\hline \multicolumn{5}{|l|}{ At enrolment } \\
\hline Total Homes Enrolled & 130 & 53 & 141 & 324 \\
\hline Number of homes with no working alarm pre & 42 & 15 & 31 & 88 \\
\hline Number of homes with some working alarms pre & 88 & 38 & 110 & 236 \\
\hline Percentage without any working alarms pre $(95 \% \mathrm{Cl})$ & $32.3 \%$ (24.2 to 40.4$)$ & $28.3 \%(16.0$ to 40.6$)$ & $22.0 \%(15.1$ to 28.9$)$ & $27.2 \%(22.3$ to 32.0$)$ \\
\hline Mean number of alarms working on arrival at home $(95 \% \mathrm{Cl})$ & 1.18 (0.98 to 1.18$)$ & $1.30(0.98$ to 1.62$)$ & $1.43(1.25$ to 1.60$)$ & 1.31 (1.18 to 1.43$)$ \\
\hline Mean number of alarms installed (SE) & $2.13(0.09)$ & $2.10(0.13)$ & $2.09(0.09)$ & $2.10(0.06)$ \\
\hline \multicolumn{5}{|l|}{ At follow-up } \\
\hline Number of homes with no working alarm post & 13 & 7 & 17 & 37 \\
\hline Percentage without any working alarms post & $10.0 \%$ & $13.2 \%$ & $12.1 \%$ & $11.4 \%$ \\
\hline Increase in per cent with working alarms & $22.3 \%$ & $15.1 \%$ & $9.9 \%$ & $15.8 \%$ \\
\hline Percentage of decrease in homes without working alarms & $69.0 \%$ & $53.3 \%$ & $45.2 \%$ & $58.0 \%$ \\
\hline Mean number of working alarms post & 2.06 & 2.00 & 1.89 & 1.96 \\
\hline Increase in number of working alarms per home $(95 \% \mathrm{Cl})$ & 0.88 (0.66 to 1.11$)$ & $0.70(0.25$ to 1.14$)$ & $0.45(0.24$ to 0.66$)$ & $0.65(0.50$ to 0.80$)$ \\
\hline Percentage of increase in number of working alarms & $42.9 \%$ & $34.9 \%$ & $23.7 \%$ & $33.2 \%$ \\
\hline Mean time to follow-up (and SE) & $721(22)$ & $867(39)$ & $646(17)$ & $715(14)$ \\
\hline \multicolumn{5}{|l|}{ Method operability determined at follow-up } \\
\hline Homes where alarms were tested at follow-up & 117 & 49 & 130 & \\
\hline Resident report of alarm operability only & 13 & 4 & 11 & \\
\hline Per cent tested & $90.0 \%$ & $92.5 \%$ & $92.2 \%$ & \\
\hline
\end{tabular}

Working alarms are hard-wired or have working batteries. 
education helped to explain alarm operability. Significance of the treatment effect was clearer in regressions that controlled for differences in KAB. The estimated increase averaged one more working alarm at follow-up for every three Practice or Full Education homes $(p=0.01,95 \%$ CI 0.09 to 0.56$)$. Practice increased average number of working alarms per home by 0.37 $(\mathrm{p}=0.027,95 \%$ CI 0.04 to 0.70$)$, which is more than the 0.30 increase $(\mathrm{p}=0.020,95 \%$ CI 0.05 to 0.55$)$ with Full Education (see online supplementary appendix table C2). The differential increase between the two arms before adjusting for KAB responses was minimal and the effects were statistically similar $(p=0.971$, see online supplementary appendix table C4).

Controlling for alarm status preinstallation, logistic regression (table 4) showed treatment homes had a significantly higher probability of having at least one working alarm at follow-up $(\mathrm{OR}=2.77, \mathrm{p}=0.032,95 \% \mathrm{CI} 1.09$ to 7.03$)$. An OR of 2.77 relative to Current Norm suggests $64 \%$ ((2.77 to 1.00$) / 2.77)$ of the increase in homes with working alarms results from improved education and the remainder would have resulted if installers instead had delivered Current Norm. ${ }^{19}$ At follow-up, Practice and Full Education homes had a 26\% lower regression-adjusted probability than Current Norm homes of having no working alarms $(9.7 \%$ vs $13.1 \%$, percentages not tabulated). Full Education yielded a significant increase $(\mathrm{OR}=2.68, \mathrm{p}=0.051,95 \%$ CI 0.99 to 7.24 ; see online supplementary appendix table C3). The Practice arm experienced a similar increase but (due to small sample size) it was marginally significant $(\mathrm{OR}=3.00, \mathrm{p}=0.097,95 \%$ CI 0.82 to 11.04). Again, effects in these two arms were statistically similar before adjusting for KAB responses $(p=0.967$, see online supplementary appendix table C5).

As online supplementary appendix $\mathrm{C}$ reports, variations in the regression models tested their sensitivity to analytic choices. Magnitude and significance of the treatment effect changed minimally.

\section{DISCUSSION}

This randomised trial shows that an educational approach based on social-cognitive theory that incorporates hands-on practice installing alarm batteries, with or without the health beliefs model component, greatly increases smoke alarm operability at follow-up. Adding practice to conventional fire department education made it three times more likely that a home had a working alarm 2 years later. It also increased the number of working alarms per installation home by $17 \%(0.32 / 1.89$ alarms per Current Norm home). Replacing the fire department education with education built around the health belief model, however, did not further improve smoke alarm operability. Gains in both outcomes with education including theory-based practice were statistically significant at the 95\% confidence level with stable coefficients across statistical models. Education incorporating practice took roughly the same amount of time that a fire department or community group typically spends providing safety messages during an alarm installation.

Alarm status an average of 24 months postinstallation in Current Norm comparison homes-12.1\% without working alarms-was comparable to other programmes with fire department education. Among homes in rural Iowa receiving comparable alarms and batteries, $1.9 \%$ had no functioning alarms at 12 months $^{20}$ and $11.6 \%$ had none at 42 months. ${ }^{14}$ A Seattle study of owner-occupied homes in low income areas installed one comparable alarm per home; $22.9 \%$ were not working within 15 months. ${ }^{13}$ Across five states, 5-13\% of high-risk homes had no working alarms 6-12 months postinstallation including $11 \%$ in Baltimore. $^{21}$

\section{Limitations}

This study is not fully generalisable. It largely reached lowincome black and elderly white households. In the few Hispanic households, we often left materials in Spanish but delivered minimal education beyond hands-on practice. Thus, it is unclear if this intervention would work in concentrated Hispanic neighbourhoods. We also tested the intervention with virtually no Asians, non-elderly whites, or higher income households. The intervention probably would apply to combined smoke-carbon monoxide alarms but is not relevant to more costly alarms with lithium batteries that cannot be changed.

Recruitment problems limited statistical power. They also kept installers from reaching some homes that fire department personnel could access. That again could limit the reach of the findings. This seems unlikely to be an issue, however, since outcomes were not different in Baltimore where fire personnel helped staff to access homes.

Another limitation was that we recorded the number of alarms working when we arrived at each home but not the

Table 3 Increase in working alarms at follow-up relative to increase with current norm

\begin{tabular}{|c|c|c|c|c|}
\hline \multirow[b]{2}{*}{ Independent variable } & \multicolumn{2}{|l|}{ Model 1} & \multicolumn{2}{|l|}{ Model 2} \\
\hline & Coefficient $(95 \% \mathrm{CI})$ & p Value & Coefficient $(95 \% \mathrm{CI})$ & p Value \\
\hline Constant & $0.94(0.61$ to 1.28$)$ & $>0.001$ & $-0.04(-1.23$ to 1.14$)$ & 0.940 \\
\hline Full education or practice & $0.26(0.03$ to 0.49$)$ & 0.028 & $0.32(0.09$ to 0.55$)$ & 0.007 \\
\hline Baltimore & $0.35(0.07$ to 0.63$)$ & 0.015 & $0.25(-0.03$ to 0.53$)$ & 0.083 \\
\hline Pilot test home & $0.12(-0.31$ to 0.55$)$ & 0.579 & $0.08(-0.35$ to 0.51$)$ & 0.718 \\
\hline Number of alarms working pre-intervention & $-0.75(-0.85$ to 0.65$)$ & $>0.001$ & $-0.75(-0.86$ to -0.065$)$ & $>0.001$ \\
\hline Number of alarms installed & $0.22(0.11$ to 0.33$)$ & $>0.001$ & $0.20(0.09$ to 0.31$)$ & 0.001 \\
\hline Income group (DK=0) & & & $0.15(-0.07$ to 0.38$)$ & 0.180 \\
\hline Income question refused & & & $0.16(-0.09$ to 0.42$)$ & 0.211 \\
\hline Belief that alarms reduce worry & & & $0.18(0.01$ to 0.35$)$ & 0.041 \\
\hline Belief that false alarms make smoke alarms annoying & & & $-0.12(-0.24$ to -0.002$)$ & 0.046 \\
\hline Number of cases & & 324 & & 308 \\
\hline Adjusted $\mathrm{R}^{2}$ & & 0.45 & & 0.47 \\
\hline
\end{tabular}


Table 4 Increase in homes with at least one working alarm at follow-up relative to increase with Current Norm

\begin{tabular}{|c|c|c|}
\hline Independent variable & OR $(95 \% \mathrm{Cl})$ & p Value \\
\hline Full Education or Practice & $2.77(1.09,7.03)$ & 0.03 \\
\hline Baltimore & $1.83(0.58$ to 5.80$)$ & 0.30 \\
\hline Pilot test home & 0.69 (0.18 to 2.67$)$ & 0.60 \\
\hline Spanish materials & $0.22(0.02$ to 2.06$)$ & 0.18 \\
\hline Black race/ethnicity & $1.60(.052$ to 4.97$)$ & 0.42 \\
\hline More than 3 children & $0.19(0.03$ to 1.04$)$ & 0.06 \\
\hline Education & $0.91(0.62$ to 1.34$)$ & 0.62 \\
\hline Income group & $1.45(0.79$ to 2.65$)$ & 0.23 \\
\hline Income question refused & $1.98(0.81$ to 4.82$)$ & 0.14 \\
\hline GE 1 working alarm pre & $1.80(0.72$ to 4.51$)$ & 0.21 \\
\hline Resident says fire risk is large & 1.38 (0.99 to 1.93$)$ & 0.06 \\
\hline Resident says alarms save lives & $0.49(0.18$ to 1.37$)$ & 0.17 \\
\hline Resident says alarms reduce worry & 1.57 (0.86 to 2.85$)$ & 0.14 \\
\hline Resident says batteries are costly & $2.27(0.91$ to 5.63$)$ & 0.08 \\
\hline Number of perceived barriers & $0.80(0.58$ to 1.10$)$ & 0.16 \\
\hline Cases & & 263 \\
\hline Pseudo $\mathrm{R}^{2}$ & & 0.14 \\
\hline \multicolumn{3}{|c|}{$\begin{array}{l}\text { The coefficient for Full Education or Practice shows the increased likelihood of a } \\
\text { treatment arm home having working alarms at follow-up relative to the comparison } \\
\text { arm. Education runs from } 0 \text { for elementary school to } 6 \text { for graduate school. Income } \\
\text { group is set to } 0 \text { if refused and separated into } 4 \text { income groups above that. The count } \\
\text { of perceived barriers was computed from KAB items 8-14. } \\
\text { KAB, knowledge, attitudes and behaviour. }\end{array}$} \\
\hline
\end{tabular}

number working when the installation visit was completed. We counted alarms we installed and hard-wired alarms which remained in operation, but did not record the number of existing alarms that we left in place and equipped with fresh batteries. Consequently, it was impossible to analyse what percentage of working alarms were still working 2 years later, the outcome measured in two studies published after we fielded our study. ${ }^{13} 14$ Those studies also found that alarm function varies with location, with kitchen alarms less likely to remain functional. We could not adjust for that bias because we did not record alarm locations at follow-up.

The estimated effect would underestimate if asking the KAB questions reinforced normal fire department education, making it more effective. The $\mathrm{KAB}$ responses helped to explain alarm operability at follow-up (and also at enrolment). Thus, it is puzzling that Full Education, which was designed to change KAB, did not increase operability more than typical education plus hands-on practice. Unfortunately, our follow-up interviews often were not with the person we educated at installation. Therefore, we could not ask those we educated the KAB questions again at follow-up and analyse learning outcomes.

\section{Conclusions}

With the education time and training available, despite its limitations, this study provides significant evidence that fire departments and community groups can achieve greater smoke alarm operability by adopting theory-based health education. The key appears to be hands-on practice-testing and changing an alarm battery and using the hush button. Installation programme staff have the capability to perform this type of education with minimal training or adherence to a script. Although the study was not designed as an equivalency trial, we found that the full health belief model and hands-on practice plus typical education produced statistically similar outcomes.

\section{What is already known on this subject}

Working smoke alarms reduce deaths in residential fires by at least $48 \%$. Getting households to keep alarms operational, however, has proven difficult. Two years after programmes install smoke alarms in low-income homes, one-fourth lack working batteries.

\section{What this study adds}

Without increasing installation time, installers can increase smoke alarm operability through hands-on practice. Two years after installation, if residents have practiced installing batteries and hushing alarms, 16\% more alarms should be working and probability of having no working alarms should be $26 \%$ lower.

Acknowledgements All authors would like to thank Bishop Dennis Madden and Mary Ellen Fise and the priests of the Baltimore Archdiocese and the Baltimore and Prince Georges' County fire departments for their assistance in recruitment for this project. The fieldwork was virtually all performed by health educators Tarik Chapman and Tabatha McNeill and installers Richard Bowen and Jenee Cannady. Lester Becker and to a lesser extent Doreen Branch, and Denise Nguyen played key roles in designing and implementing the project's instrumentation and fieldwork protocols.

Contributors All authors contributed to interpretation of the results and revision of the manuscript and approved the final manuscript as submitted. TRM served as principal investigator, leading the effort throughout, performing data cleaning and statistical analysis, and drafting the manuscript. He is the guarantor. GB and ACG led development of the educational scripts and instrumentation. GB shepherded the manuscript through CDC clearance. MFB developed the concept and basic design of the study. SB performed statistical analyses, as well as leading data cleaning and survey instrument linkage. MSS supervised much of the fieldwork.

Funding This research was supported in part by grant U17/CCU323334 from the National Center for Injury Prevention and Control, US Department of Health and Human Services, Centers for Disease Control and Prevention (CDC). The findings and conclusions reported are those of the authors and do not necessarily represent the official position of the CDC.

\section{Competing interests None.}

Ethics approval Pacific Institute for Research and Evaluation's IRB.

Provenance and peer review Not commissioned; externally peer reviewed.

Data sharing statement $A$ deidentified data set with open-ended responses removed is available from the corresponding author. Consent for data sharing was not obtained from participants, but the presented data are anonymised and risk of identification is minimal.

\section{REFERENCES}

1 Ahrens M. Smoke alarms in U.S. home fires. Quincy, MA: National Fire Protection Association, 2009.

2 Runyan CW, Bangdiwala SI, Linzer MA, et al. Risk factors for fatal residential fires. N Engl J Med 1992;37:859-63.

3 Istre GR, McCoy MA, Moore BJ, et al. Preventing deaths and injuries from house fires: an outcome evaluation of a community-based smoke alarm installation programme. Inj Prev 2014;20:97-102.

4 Ta VM, Frattaroli S, Bergen G, et al. Evaluated community fire safety interventions in the United States: a review of current literature. J Community Health 2006;31:176-97.

5 Ballesteros MF, Kresnow M-J. Prevalence of residential smoke alarms and fire escape plans in the U.S.: results from the second Injury Control and Risk Survey (ICARIS-2). Public Health Rep 2007;122:224-31.

6 Poehlman J, Flanigan T, Brown D, et al. Evaluation of the effectiveness of the Smoke Alarm Installation and Fire Safety Education (SAIFE) program: Final Report. Research Triangle Park, NC: RTI International, 2010. 
7 Mickalide A, Validzic A. Smoke alarm maintenance in low-income families. Am J Public Health 1999;89:1584-85.

8 Jones AR, Thompson CJ, Davis MK. Smoke alarm ownership and installation: a comparison of a rural and a suburban community in Georgia. J Community Health 2001:26:307-29.

9 Liu $Y$, Holland AE, Mack K, et al. Disparities in the prevalence of smoke alarms in U.S. households: conclusions drawn from published case studies. I Safety Res 2011:42:409-13.

10 DiGuiseppi C, Goss CW, Higgins JP. Interventions for promoting smoke alarm ownership and function. Cochrane Library 2010 doi: 10.1002/14651858. CD002246.

11 Chen L, Gielen AC, McDonald EM. Validity of self-reported home safety practices. Inj Prev 2003;9:73-5.

12 Thompson CJ, Jones AR, Davis MK, et al. Do smoke alarms still function a year after installation? A follow-up of the Get-Alarmed Campaign. J Community Health 2004;29:171-81.

13 Mueller BA, Sidman EA, Alter $\mathrm{H}$, et al. Randomized controlled trial of ionization and photoelectric smoke alarm functionality. Inj Prev 2008;14:80-6.

14 Peek-Asa C, Yang J, Hamann C, et al. Smoke alarm and battery function 42 months after installation: a randomized trial. Am J Prev Med 2010;39:368-71.
15 McDonald EM, Gielen AC. House fires and other unintentional home injuries, Chapter 13. In: Gielen AC, Sleet DA, DiClemente RJ, eds. Injury and Violence Prevention. Behavioral Science Theories, Methods, and Applications. San Francisco, CA: Jossey-Bass, 2006:274-96.

16 Ballesteros MF, Jackson ML, Martin MW. Working toward the elimination of residential fire deaths: the centers for disease control and prevention's Smoke Alarm Installation and Fire Safety Education (SAIFE) program. J Burn Care Rehabil 2005;26:434-9.

17 Gielen AC, McKenzie LB, McDonald EM, et al. Using a computer kiosk to promote child safety: results of a randomized, controlled trial in an urban pediatric emergency department. Pediatrics 2007;120:330-9.

18 Glanz K, Rimer BK, Lewis FM, eds. Health behavior and health education: theory, research, and practice. 3rd edn. San Francisco, CA: Jossey-Bass, 2002.

19 Rothenberg RB, Hahn RA. Appendix J: measures of attribution. In: Haddix AC, Teutsch SM, Shaffer PA, Dunet DO, eds. Prevention effectiveness: a guide to decision analysis and economic evaluation. New York, NY: Oxford University Press, 1996:193-202.

20 Yang J, Peek-Asa C, Jones MP, et al. Smoke alarms by type and battery life in rural households: a randomized controlled trial. Am J Prev Med 2008:35:20-4.

21 Harvey $P$, Aitken $M$, Ryan $G$, et al. Strategies to increase smoke alarm use in high-risk households. J Community Health 2004;29:375-85. 